\title{
Multilevel Power Conditioner for Grid-Connected Photovoltaic Applications
}

\author{
G. Grandi, Member, IEEE, D. Ostojic, C. Rossi, Member, IEEE, D. Casadei, Senior Member, IEEE ${ }^{l}$
}

\begin{abstract}
A novel scheme for three-phase grid-connected photovoltaic (PV) generation systems is presented in this paper. The proposed scheme is based on two insulated strings of PV panels, each one feeding a standard two-level three-phase voltage source inverter (VSI). Inverters are connected to grid by a threephase transformer with the open winding configuration on inverters side. The resulting conversion structure performs as a multilevel power active filter, doubling the power capability of a single VSI with given current rating. An original control method has been introduced to regulate the dc-link voltages of each VSI. The proposed algorithm has been verified by numerical simulations with reference to different operating conditions. The results confirm the effectiveness of the whole conversion structure.
\end{abstract}

\section{INTRODUCTION}

Photovoltaic (PV) panels produce electricity, using no moving parts, consuming no fuel, and creating no pollution. Because of constantly growing energy demand, grid-connected photovoltaic systems are becoming more and more popular, and many countries have permitted, encouraged, and even funded distributed power generation systems. Yet the technology presents shortcomings such are high initial installation cost and low energy conversion efficiency, requiring constant improvement of both cell and power converter technology [1].

One of the classification criteria for PV systems is the way in which relatively low and weather-dependant voltage is "boosted" to reach grid voltage level. A series connection of adequate number of panels seems as the simplest solution but it involves considerably large number of panels in series. Therefore the output current and performance of the system is constrained by the weakest cell, including partial shadowing or failure [2]. Remaining solutions are to include dc to $\mathrm{dc}$ converter stage, or transformer, or even both. In many countries national electric code requires transformer's presence to achieve galvanic insulation of panels with respect to the network. Even if topology includes transformer (either high- or line-frequency), the system with a dc/dc converter will operate over a wider input voltage range but with higher cost and lower conversion efficiencies at most operating points. Transformerless and high-frequency transformer are preferred for omitting bulky LF transformer and already commercially presented, but limited to single-phase output with powers up to few $\mathrm{kW}$. The restrictions arise from switching losses and limited power of the HF magnetic components. Hence PV converter with line-frequency transformer is prevailing in higher power range, i.e., from few tens of $\mathrm{kW}$ up to $1000 \mathrm{~kW}$, con-

\footnotetext{
${ }^{1}$ Gabriele Grandi, Darko Ostojic, Claudio Rossi, and Domenico Casadei are with the Dept. of Electical Engineering, University of Bologna, Bologna, Italy (e-mail: <name.surname>@mail.ing.unibo.it).
}

tributed by the fact that LF transformer's cost per watt decreases as rated power increases.

A novel topology for PV grid-connected systems is proposed in this paper. It utilizes dual inverter structure connected to open-end primary windings of a standard three-phase transformer. Each inverter can be directly coupled with the panels, as shown in Fig. 1, or through dc/dc stage, an option available for all PV converters [1]. The secondary windings are connected to the grid with traditional either delta or star configuration. Note that the transformer contributes with its leakage inductance to the ac-link inductance which is always necessary for the grid connection of a VSI.

The resulting three-phase converter is able to operate as a multilevel inverter, with the benefit of reduced harmonic distortion and lower $\mathrm{dv} / \mathrm{dt}$ in the output voltages. The main advantage of this topology is the simplified hardware structure with respect to traditional multilevel inverters, increasing both the effectiveness and the reliability in medium- and highpower applications. Also, it can use standard six-transistor configuration readily available also as modules, without additional diodes and switches. A control algorithm with standard PI controllers is proposed to achieve commanded values of de voltages necessary for maximum power point tracking (MPPT) of PV panels. Beside power generation the system can function as an "active filter", with the additional capabilities of load balancing, harmonics compensation and reactive power injection. Complete analysis, together with numerical simulations, are presented for verifying system performance in the case of different variations of the solar irradiance.

\section{DUAL INVERTER TOPOLOGY}

In low voltage high power applications designer inevitably encounters the problem of high currents exceeding available switch's ratings. One common way to overcome this limitation is paralleling of more switches, but it brings drawbacks in

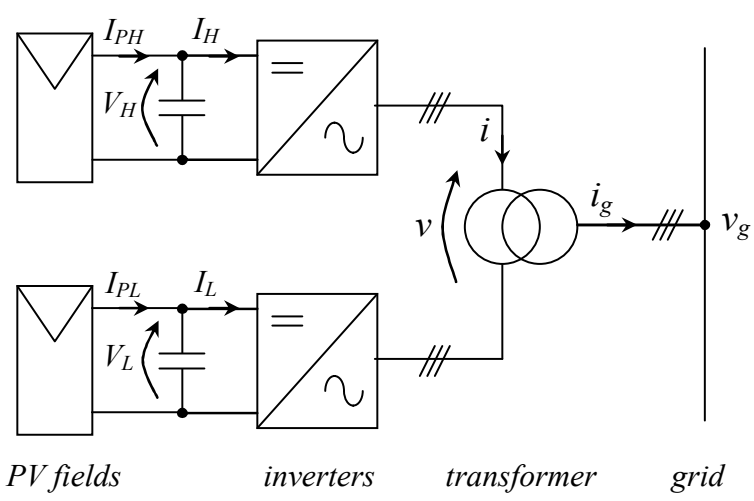

Fig. 1. Proposed dual-inverter configuration. 
current protection, circuitry complexity and current sharing. A viable solution to overcome this constraint is multilevel inverter. Among many proposed solutions, three-level converters are a good tradeoff solution between performance and cost in high-voltage and high-power systems [3], [4]. The main advantages of three-level inverters are reduced voltage ratings for the switches, good harmonic spectrum (making possible the use of smaller and less expensive filters), and good dynamic response. In particular, the output voltage waveform of the conversion unit has a multilevel behavior, producing up to nine output levels of phase voltage. Since dual two-level inverter (Fig. 1) can give the same output voltage as three-level inverter, it makes more convenient solution. Another advantage is lack of voltage balance problems that occur in multi-level converters [5]. However, the control complexity increases compared to conventional VSI.

In comparison with standard three-phase inverter, the dual inverter achieves double rated power with a double number of switches, resulting in the same switch utilization. It can be said that the switches in those two cases are just repartitioned. The benefit lays in the fact that dual converter's output rated current is halved for the same rated power and voltage. Another benefit is the ability to produce up to nine output voltage levels versus only five of standard three-phase inverter, thus having output voltage less distorted. It makes easier to meet demands of the standards given by the utility companies regarding current harmonics with smaller passive filter components.

The presence of transformer enables choice of low dc voltage. In this case, only parallel connection of panels can be considered. The resulting PV string voltage is generally between 30-50 V, which allows use of low-voltage MOSFETs. These types of MOSFETs are widely used in automotive applications and they are very cheap semiconductor devices. Furthermore those components feature good efficiency, since their on-state resistance is a strong decreasing function of the blocking voltage rating. However, maximum power rating of converter using low PV string voltage is limited to few tens of $\mathrm{kW}$. For higher powers the proposed topology can be utilized with higher dc side inverter's voltage (400-700 V). Demanded dc voltage range can be directly obtained by increased PV string voltage with series connection of more panels. Another possibility is inclusion of $\mathrm{dc} / \mathrm{dc}$ converter, which simultaneously takes over role of MPP tracker, enabling optimal and constant dc voltage for dual inverter. For even higher powers (above few hundred $\mathrm{kW}$ ) converter can be directly connected to medium voltage level $(10-20 \mathrm{kV})$.

Beside somewhat higher complexity, the main drawback in comparison to standard inverter configuration is the potential path for the zero sequence currents. If dual inverter is supplied from single dc source, it requires implementation of component (reactor or transformer) with high zero-sequence impedance to suppress corresponding current flow. Both options mean higher cost and dimensions of the system. Another possible solution is application of voltage modulation algorithm which doesn't produce zero sequence voltage, but this leads to lower utilization of available voltage by $15.5 \%$ and thus higher costs of the system [6]. In some applications, such is $\mathrm{PV}$, it is simple and convenient to separate panels in two strings since string subdivision is commonly accepted array topology. Although division prevents undesired zero sequence current from flowing, it should be noted that it requires two set of sensors (for each string) and makes control algorithm more complicated.

With reference to the scheme on Fig. 1, using space vector representation, the output voltage vector $\bar{v}$ of the multilevel converter is given by the contribution of the voltage vectors $\bar{v}_{H}$ and $\bar{v}_{L}$, generated by inverter $H$ and $L$ respectively [7]:

$$
\bar{v}=\bar{v}_{H}+\bar{v}_{L} .
$$

The combination of the eight switching configuration for each inverter yields total 64 switching states corresponding to 19 different output voltage vectors, including zero vector. The resulting hexagonal locus can be subdivided in two areas, as represented in Fig. 2: the inner hexagon and the outer belt [8]. In a grid-connected application voltage vector is always positioned in the outer belt, which means both inverters " $H$ " and " $\mathrm{L}$ " are contributing to the output voltage.

\section{INVERTER CONTROL}

The proposed system is symmetric having both inverters with equal ratings and two equal groups (strings) of panels supplying them. Nevertheless two distinct voltage controllers have to be implemented to compensate unavoidable mismatches, originating from cell production nonidealities or small differences in cleanness and/or position. The primary control task is voltage regulation of both PV strings to accomplish MPP for both of them. In the following, the voltage control is described in more detail while the MPP and other necessary supervisory tasks of the system control are not discussed further. It is important to note that control task is much more complex than in case of a single inverter configuration, because the proposed system is multivariable. While in single inverter configuration the only variable being controlled is ac current, in case of dual inverter ac current but nonetheless inverter's output ac voltages sharing between " $H$ " and " $L$ " inverters is influencing the state of the system. In this paper a novel control algorithm based on simple PI controllers is proposed. The problem is somewhat similar to power sharing problem investigated in automotive applications, where proper multilevel voltage modulation strategy has been addressed [8].

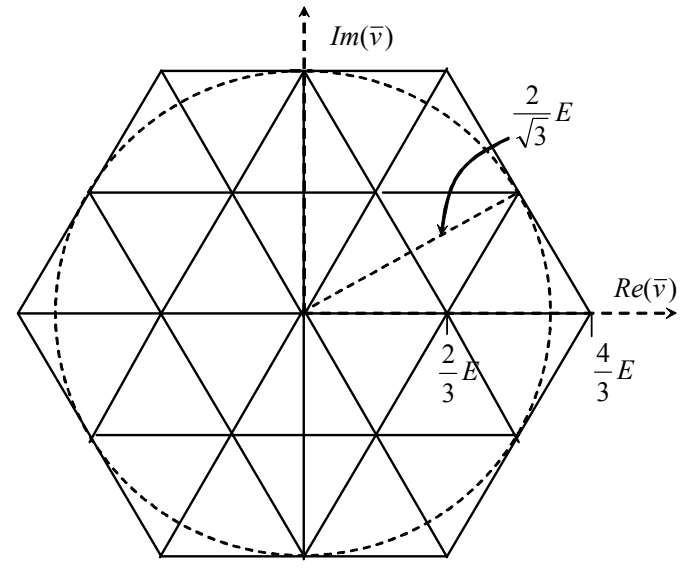

Fig. 2. Dual inverter voltage vector plot in the case $V_{H}=V_{L}=E$. 


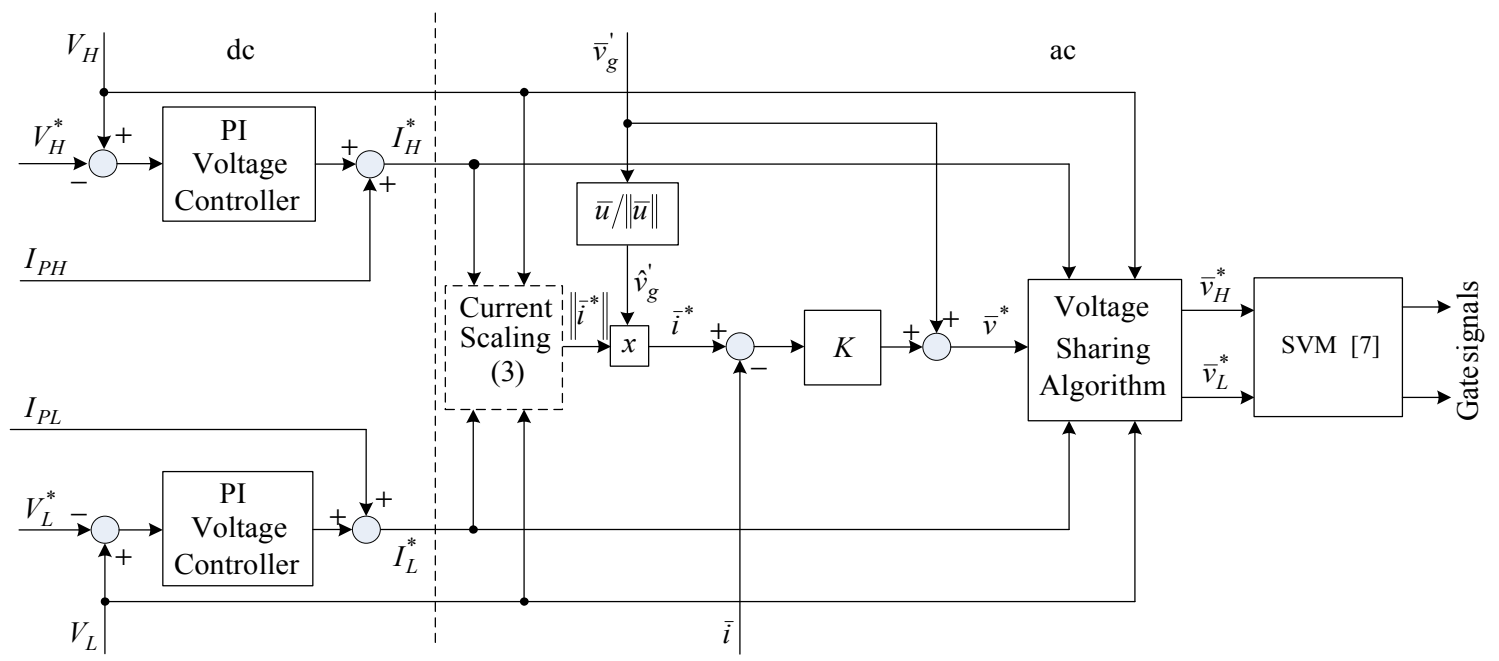

Fig. 3. Block diagram of proposed control system.

In [9] the more complex approach of $L Q R$ techniques based on state-space models is considered, whereas in [10] an independent control of each inverter is proposed for integrated starter-alternator drive in automotive application.

The two de voltages $\left(V_{H}, V_{L}\right)$ are controlled by two proportional-integral controllers, giving as output the reference of two dc currents $\left(I_{H}^{*}, I_{L}^{*}\right)$. A feed-forward action can be added in order to compensate sudden changes in PV currents $\left(I_{P H}\right.$, $\left.I_{P L}\right)$, as shown in Fig. 3. Its utilization depends on the current transducer's availability and required response dynamic. The inverter output current reference is calculated based on the previous controllers references and power balance equation in steady-state. If the inverter current is injected into the grid in phase with the grid voltage, the power balance yields

$$
V_{H} I_{H}+V_{L} I_{L}=3 V_{g}^{\prime} I
$$

where $V_{g}^{\prime}$ is the grid voltage seen from the inverters' side (RMS) and $I$ is inverters' ac output current (RMS). Note that in (2) both inverter and transformer losses are neglected. Thus, from (2) current reference can be obtained as

$$
I^{*}=\frac{1}{3} \frac{V_{H} I_{H}^{*}+V_{L} I_{L}^{*}}{V_{g}^{\prime}} .
$$

The current injected into the grid is assumed to be in phase with grid voltage, i.e. having only active component, as stated above. The resulting reference current space vector $\bar{i}^{*}$ for the converter is

$$
\bar{i}^{*}=I^{*} \hat{v}_{g}
$$

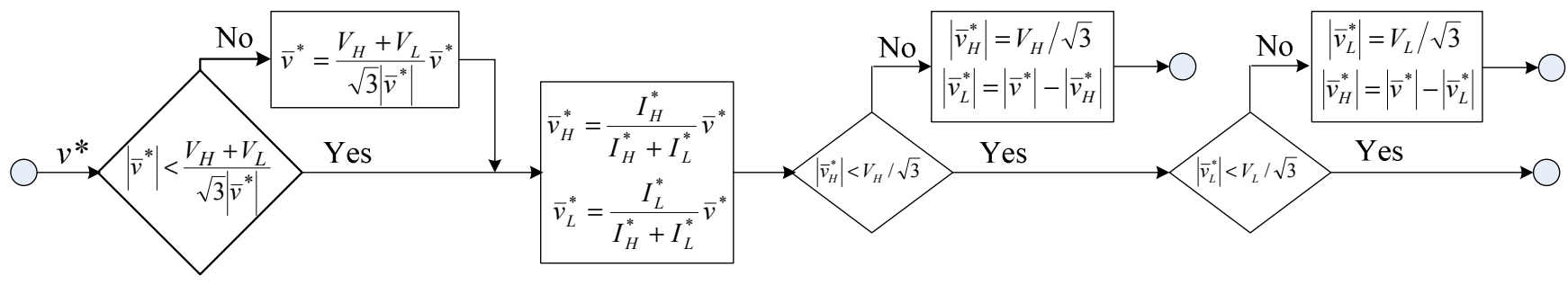

being $\hat{v}_{g}$ the unity space vector of the grid voltage. It can be noted that reactive and/or harmonic compensation current references can be added if active power filter operating conditions are required.

The reference voltage space vector $\bar{v}^{*}$ for the converter can be determined by introducing the voltage equation across the total ac link inductance $L$ :

$$
\bar{v}=L \frac{d \bar{i}}{d t}+\bar{v}_{g}^{\prime},
$$

being $\bar{v}_{g}^{\prime}$ the grid voltage seen from the inverters' side. Then, by neglecting the magnetizing current of the transformer, the reference voltage $\bar{v}^{*}$ can be calculated on the basis of the actual current error as follows

$$
\bar{v}^{*}=K\left(\bar{i}^{*}-\bar{i}\right)+\bar{v}_{g}^{\prime} .
$$

The individual inverter reference voltages $\bar{v}_{H}^{*}, \bar{v}_{L}^{*}$ can be determined on the basis of the following equations

$$
\bar{v}_{H}^{*}=\frac{I_{H}^{*}}{I_{H}^{*}+I_{L}^{*}} \bar{v}^{*}, \quad \bar{v}_{L}^{*}=\frac{I_{L}^{*}}{I_{H}^{*}+I_{L}^{*}} \bar{v}^{*} .
$$

Further, it has to be provided that both references are within range of achievable output voltage of particular inverter, which depends on their de voltages. This is an issue on which this topology differs from case of a single inverter topology, where no problems arise when the voltage demand exceeds available dc voltage. Here total voltage reference must be satisfied, so in case of voltage saturation of one inverter the second has to

Fig. 4. Detail of the proposed control scheme to avoid problems due to inverter voltage saturation. 
make up the missing part. This is achieved by the voltage sharing algorithm shown in Fig. 4.

Once the inverter reference voltages $\bar{v}_{H}^{*}$ and $\bar{v}_{L}^{*}$ are determined, the space vector modulation proposed in [7] can be applied to ensure correct multilevel voltage waveforms at the transformer open-end windings.

\section{SYSTEM IMPLEMENTATION}

The simulation model of the proposed topology and control scheme represented in Figs. 1 and 3 was implemented in MATLAB-Simulink. The component ratings used for model are based on real laboratory equipment which are used for the experimental tests. Each PV string has been electrically represented by a simple voltage generator $\left(V_{o c}=44 \mathrm{~V}\right)$ with a series resistance $\left(R_{P V}=1 \Omega\right)$, to model the hardware adopted in the preliminary experimental tests that will be shown in a future paper. The main characteristics of the whole PV power conditioner are summarized in Table I.

The value of the ac-link inductance is a tradeoff between acceptable current ripple and available dc voltage. Low inductance will give a high current ripple and will make a design more dependent on the line impedance. A high value of inductance will give a low current ripple, but simultaneously create a high voltage drop at line frequency and therefore reduce the operation range of system, increasing its cost and dimensions. Since the role of ac-link inductance is to filter output current, in that purposes could be utilized transformers leakage inductance, analogously to inverter drive applications where same role is performed by motor leakage inductance. Unfortunately, the leakage inductance of standard transformer is about two or three times lower that in a case of motor with same rated power. Hence, a modified transformer structure or an additional series inductor could be necessary to provide the required value of the ac-link inductance, especially in the case of low voltage windings.

\section{SimULATION RESULtS}

In simulation tests, reference is made to the scheme presented in Fig. 1, with a direct connection of the two PV panel strings and the two inverters. In this case the MPPT regulation is achieved by the change of inverters' dc bus voltage. Note that a possible implementation of MPPT algorithm could be similar to the one proposed in [11] and also discussed in [12], where a small voltage displacement in the operating points of the two PV strings is introduced to determine the actual slope of the $P(V)$ characteristic (i.e., the sign of $d P / d V$ ). This algorithm will be discussed and developed in a future paper.

The first case analyzed in the simulations consists of a fast change of voltage reference, $V^{*}=V_{H}{ }^{*}=V_{L}{ }^{*}$, demanded by the MPPT control algorithm as a response to the change of solar irradiation. The change is chosen to be fast in order to test ability of the control system. Fig. 5 shows the time behavior of the dc voltages. It can be seen that the system response is very good, and both voltage respond equally (their traces on figure are overlapping). The output of the dual inverter during the
TABLE I

SYSTEM PROTOTYPE CHARACTERISTICS

\begin{tabular}{|l|c|l|c|}
\hline \multicolumn{2}{|c|}{ Grid transformer } & \multicolumn{2}{c|}{ Converter } \\
\hline single-phase, $50 \mathrm{~Hz}$ & $3 \mathrm{x}$ & three-phase VSI & $2 \mathrm{x}$ \\
\hline rated voltages $(\mathrm{V})$ & $24 / 400$ & IRF2807 (parallel MOSFETs) & $6 \mathrm{x}$ \\
\hline rated power (VA) & 500 & rated dc voltage $(\mathrm{V})$ & 50 \\
\hline short circuit voltage $(\%)$ & 6.9 & rated ac current $(\mathrm{A})$ & 240 \\
\hline & & switching freq. $(\mathrm{kHz})$ & 20 \\
\hline ac-link inductance $(\mathrm{mH})$ & 0.4 & dc-bus capacitance $(\mathrm{mF})$ & 26 \\
\hline
\end{tabular}

transient (ac voltage and ac current) is shown in Fig. 6, and a zoom of the waveforms is given in Fig. 7. Note that voltage multilevel operation is achieved, and the current ripple is very small. Fig. 8 shows that grid voltage (line-to-neutral) and grid current are in phase, as expected. Since grid voltage has constant amplitude, fixed by the ac network, the variation in power generation consequent to the different operating point on the PV characteristic reflects on the grid current amplitude only.

The second case examined by simulations is summarized in Fig. 9. It represents a start-up transient of the conversion system, starting from different "open circuit" voltages of the two PV panel strings ( $42 \mathrm{~V}$ and $44 \mathrm{~V}$ ) up to the common de voltage reference $(34 \mathrm{~V})$. In particular, Figs. 10 and 11 show the details of voltage and current transients of the two PV strings, respectively. Note that the settling time is less than $100 \mathrm{~ms}$, proving the effectiveness of the two voltage regulation loops.

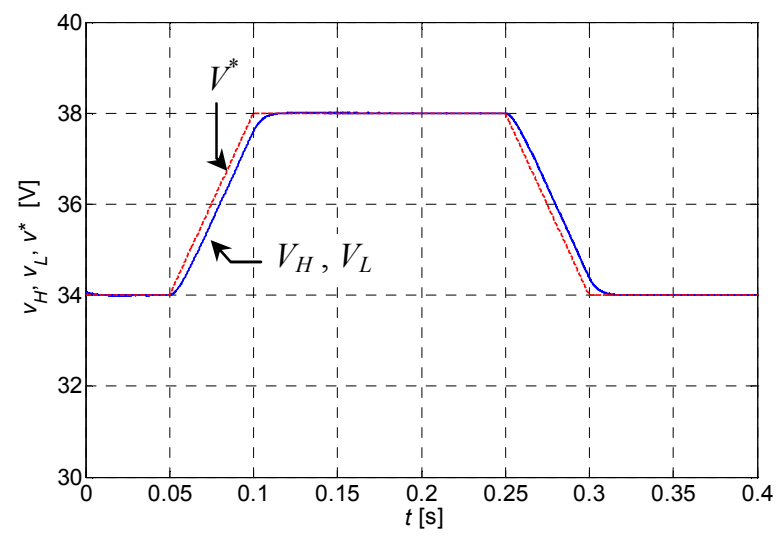

Fig. 5. Inverters de voltage (right trace) in the case of fast ramp change of the voltage reference (left trace).
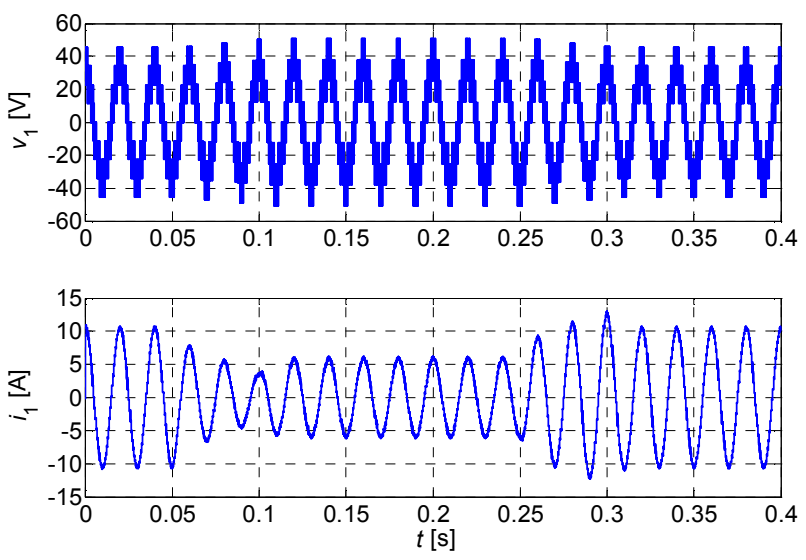

Fig. 6. Dual inverter ac voltage and ac current during the dc voltage transient represented in Fig. 5. 


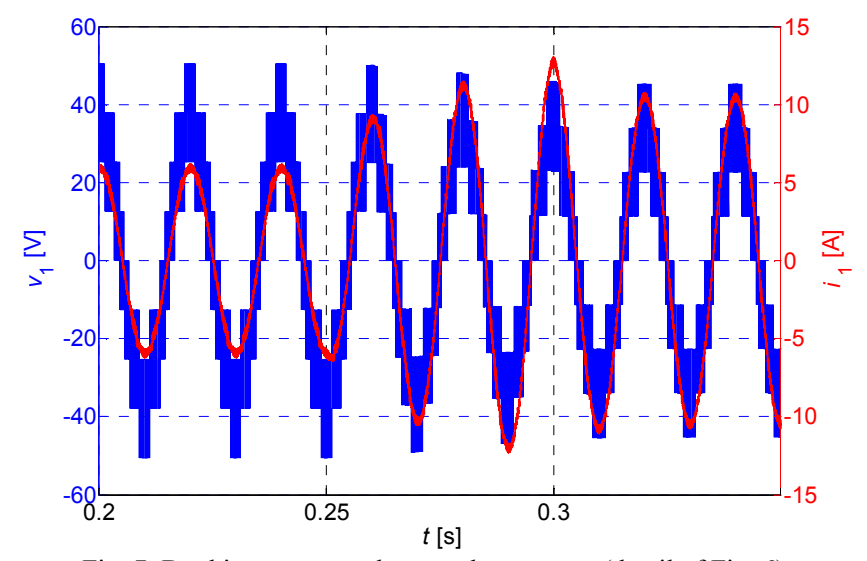

Fig. 7. Dual inverter ac voltage and ac current (detail of Fig. 6).

The last simulation represents an unbalanced change in the solar irradiance conditions consisting in sudden changes in the $\mathrm{I}-\mathrm{V}$ characteristics, with a constant dc voltage reference, as summarized in Fig. 12. It can be seen as a disturbance from the point of view of the control system. In particular, the series resistance $R_{P V}$ has been increased of $25 \%$ firstly for only one PV string and after also for the other PV string, introducing an unbalance in the PV generation system. To better explain, at the beginning of the simulation both resistances are set to $1 \Omega$, after $0.15 \mathrm{~s}$ one resistance is increased to $1.25 \Omega$, and after 0.3 $\mathrm{s}$ both resistances are set to $1.25 \Omega$. The PV strings voltages are shown in Fig. 13, showing a very small and fast transient $(<100 \mathrm{~ms})$ around the reference value $\left(V^{*}=34 \mathrm{~V}\right)$. Fig. 14 shows the PV strings currents, ranging from $10 \mathrm{~A}$ to $8 \mathrm{~A}$, as shown in the I-V characteristic of Fig. 12.

\section{CONCLUSION}

A novel conversion topology for the grid connection of a photovoltaic generation system is presented and discussed in this paper. The proposed power conditioner utilizes a dual inverter structure to extend rated maximum power and to realize ac voltage multilevel waveforms on the basis on standard three-phase inverters. The topology includes two insulated PV strings and a three-phase open-winding transformer. The resulting power conditioning system is able to behave as an active power filter capability also.

A simple and effectiveness control algorithm is introduced for the system regulation. It is able to provide power generation with unity power factor and maximum power point tracking, even in case of two unbalanced PV strings.

The whole system has been accurately designed and tested by numerical simulations, showing good performance both in steady state and transient conditions. Preliminary experimental tests are under development.

\section{REFERENCES}

[1] S. Kjaer, J. Pedersen, F. Blaabjerg, "A Review of Single-Phase GridConnected Inverters for Photovoltaic Modules," IEEE Trans. Industry Applications, Vol. 41, No. 5, Sep 2005, pp. 1292-1306.

[2] T. Shimizu, M. Hirakata, T. Kamezawa, and H. Watanabe, "Generation control circuit for photovoltaic modules," IEEE Trans. on Power Electronics, Vol. 16, No. 3, May 200, pp. 293-300.
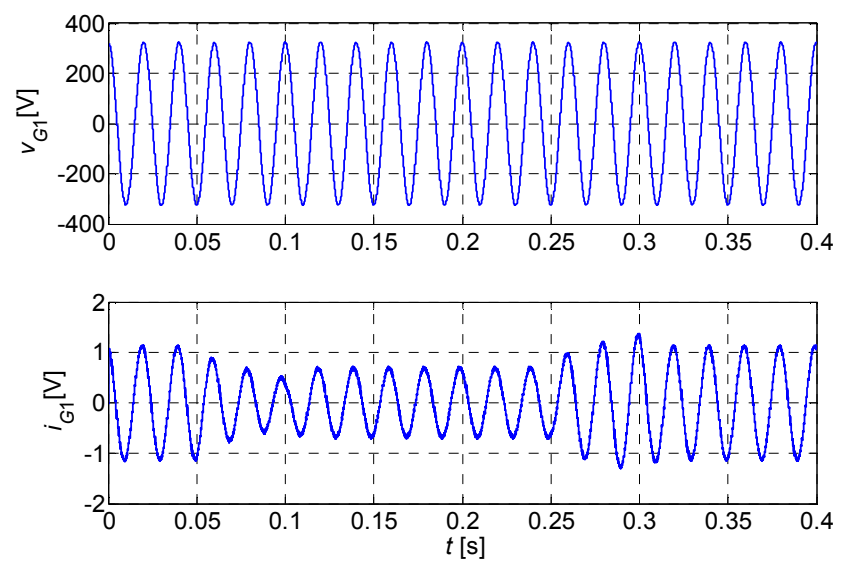

Fig. 8. Grid voltage and grid current during the dc voltage transient represented in Fig. 5.

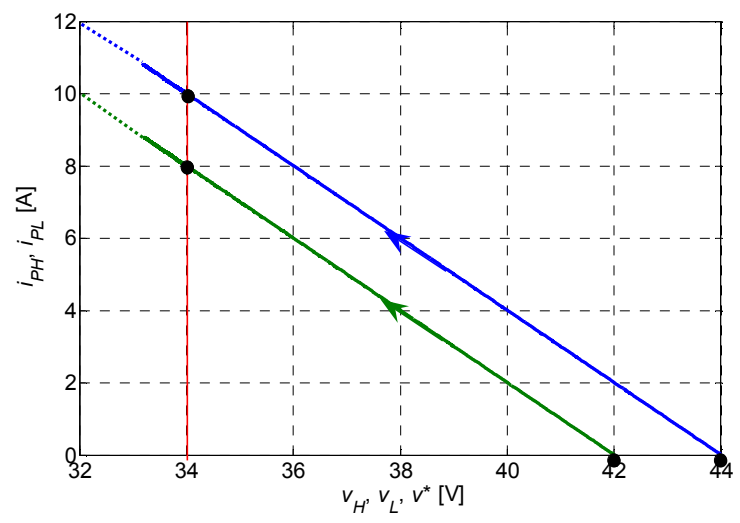

Fig. 9. Start-up transient from different open circuit voltages up to a common reference voltage on the I-V scale.

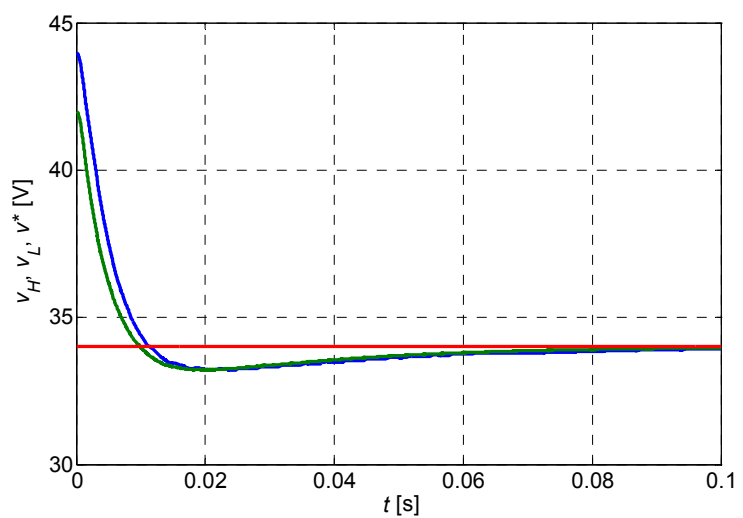

Fig. 10. Details of PV string voltages during the transient of Fig. 9.

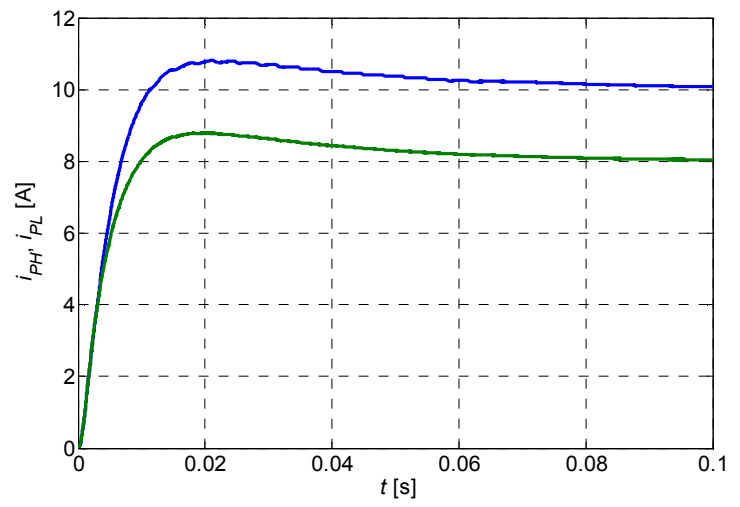

Fig. 11. Details of PV string currents during the transient of Fig. 9. 


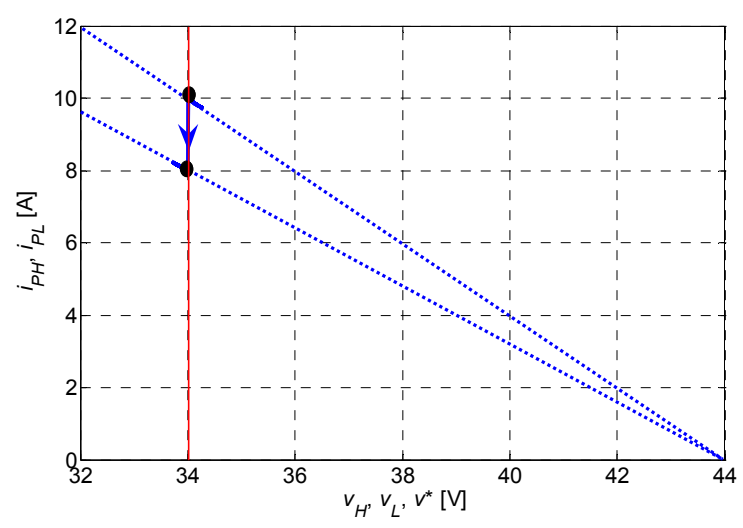

Fig. 12. I-V characteristics step change, first for one PV string and after for the other $\left(R_{P V}\right.$ from $1 \Omega$ to $\left.1.25 \Omega\right)$.

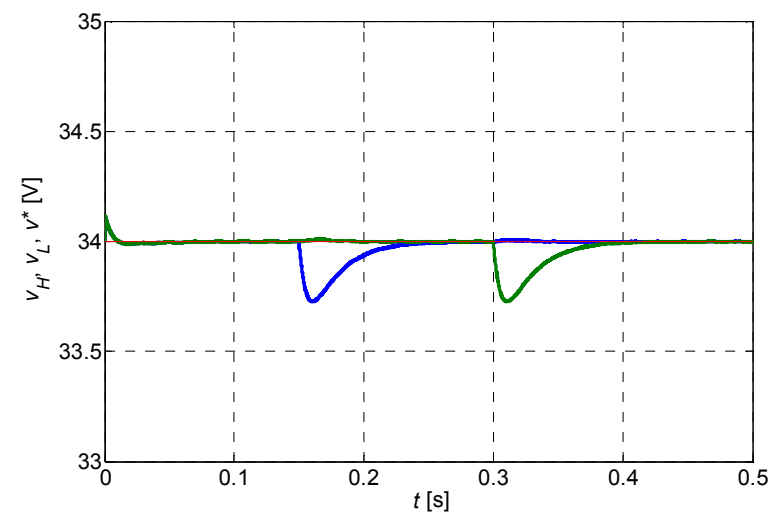

Fig. 13. Details of PV string voltages during the transient of Fig. 12.

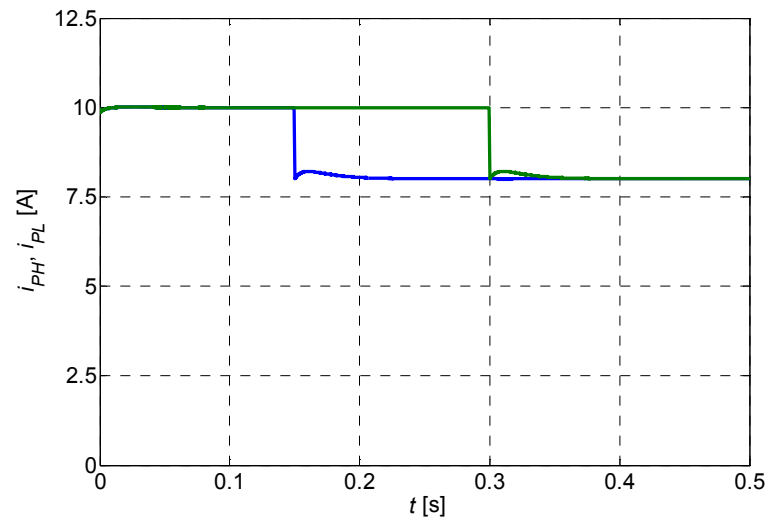

Fig. 14. Details of PV string currents during the transient of Fig. 12.

[3] I. Takahashi and Y. Ohmori, "High-performance direct torque control of an induction motor," IEEE Trans. Industry Applications, Mar. 1989, vol. 25, no. 2, pp. 257-264.

[4] Y. Kawabata, N. Yahata, M. Horii, E. Ejiogu, T. Kawabata, "SVG using open-winding transformer and two inverters," Proc. IEEE Power Electronics Specialists Conference, PESC 2004, vol. 4, pp. 3039-3044.

[5] K. Corzine, A. S. Sudhoff, C. Whitcomb, "Performance characteristics of a cascaded two-level converter," IEEE Trans. on Energy Conversion, vol. 14, No. 3, Sep. 1999, pp. 433-439.
[6] M. Baiju, K. Mohapatra, R. Kanchan, K. Gopakumar, “A dual two-level inverter scheme with common mode voltage elimination for an induction motor drive," IEEE Trans. on Power Electronics, vol. 19, No. 3, May 2004, pp. 794-805.

[7] G. Grandi, C. Rossi, A. Lega, D. Casadei, "Multilevel operation of a dual two-level inverter with power balancing capability," Proc. of IEEE Industry Applications Soc. Annual Meeting, IEEE-IAS, Tampa, Florida (USA), Oct. 8 - 12, 2006.

[8] G. Grandi, C. Rossi, A. Lega, D. Casadei, "Power balancing of a multilevel converter with two insulated supplies for three-phase six-wire loads," Proc. of $11^{\text {th }}$ European Conference on Power Electronics and Applications, EPE, Dresden (D), September 11-14, 2005.

[9] S. Alepuz, S. Busquets-Monge, J. Bordonau, J. Gago, D. Gonzalez, J. Balcells, "Interfacing Renewable Energy Sources to the Utility Grid Using a Three-Level Inverter," IEEE Trans. on Industrial Electronics, vol. 53, no. 5, Oct. 2006, pp. 1504-1511.

[10] J. Kim, J, Jung, K, Nam, "Dual-inverter control strategy for high-speed operation of EV induction motors," IEEE Trans. on Industrial Electronics, vol. 51, no. 2, Apr. 2004, pp. 312- 320.

[11] J.H. Park, J.Y. Ahn,, B.H. Cho, G.J. Yu, "Dual-module-based maximum power point tracking control of photovoltaic systems," IEEE Trans. on Industrial Electronics, Vol. 53, No. 4, June 2006, pp. 1036-1047.

[12] G. Grandi, C. Rossi, G. Fantini, "Modular Photovoltaic Generation Systems Based on a Dual-Panel MPPT Algorithm," Proc. of IEEE International Symposium on Industrial Electronics, IEEE-ISIE, Vigo (Spain), June 4-7, 2007.

Gabriele Grandi (M'00) received his M.Sc. (cum laude) and the $\mathrm{PhD}$ degrees from the Faculty of Engineering, University of Bologna, in 1990 and 1994, respectively, both in electrical engineering. In 1995 he joined the Department of Electrical Engineering, University of Bologna, as a Research Associate. Since 2005 he is an Associate Professor in the same department. His main research interests are focused on power electronic circuits and power electronic converters for renewable energy sources. He published about 80 papers on conference proceedings and international journals.

Darko Ostojic was born in Novi Sad, Serbia, in in 1976. He received the B. Sc. degree in 2002 and the M.Sc degree in 2006, both in Electrical Engineering, from the Faculty of Technical Sciences, University of Novi Sad. From 2001 to 2006 he has been Research and Teaching Assistant at the Dept. for Power Electronics and Electrical Machines, University of Novi Sad, Serbia. Since 2007 he is $\mathrm{PhD}$ student at the Dept. of Electrical Engineering, University of Bologna, Italy. His main research interests are in the field of power electronics, with particular reference to power conditioning systems for renewable energy sources.

Claudio Rossi (M05) was born in Forlì, Italy, in 1971. He received the M. Sc. degree in Electrical Engineering from the University of Bologna in 1997. In 2001 he received the Ph.D. degree at the Department of Electrical Engineering of the same University. Since 2000, he has been assistant professor of Electrical Machines, Drives and Power Electronics. His present research activity is devoted to, power electronics and drives for electric vehicles and renewable energy systems. He is a Registered Professional Engineer in Italy.

Domenico Casadei (SM04) was born in Rimini, Italy, in 1949. He received the $\mathrm{Ph} . \mathrm{D}$. degree (with honors) in electrical engineering from the University of Bologna, Bologna, Italy, in 1974. He joined the Institute of Electrical Engineering, University of Bologna, in 1975. From 1975 to 1985, he was a Research Assistant, and since 1985, he has been an Associate Professor of Electrical Drives. He is now Professor of Electrical Drives at the University of Bologna. Since 2004 he is the head of the Department of Electrical Engineering at the University of Bologna. His scientific work is related to electrical machines and drives, linear motors and power electronics. He is a Registered Professional Engineer in Italy. 